\title{
Soundness Evaluation Method Using S-N Curve for Equipment Supports Subjected to Machine Vibrations
}

\author{
Osamu Kontani ${ }^{1 *}$ Makoto Koge ${ }^{2}$ and Ryu Shimamoto ${ }^{3}$
}

\begin{abstract}
The degradation factors considered in the evaluation of long-term soundness of reinforced concrete structures in nuclear facilities in Japan are heat (high temperature), irradiation, carbonation, chloride penetration, alkali silica reaction, and machine vibration. As described in the "Guidelines for Maintenance and Management of Structures in Nuclear Facilities," the soundness evaluation of equipment supports against machine vibration is very rudimentary compared with the evaluation methods against other factors since the degradation state due to machine vibration cannot be identified until cracks are visually detected as degradation phenomena. The phenomenon of fatigue of equipment supports can be expressed using an S-N curve that shows the relation between the maximum stress ratio and the fatigue life under repeated loading. During normal operation of nuclear facilities, the maximum stress ratio of repeated load is very low and less than the long-term allowable stress level, and the fatigue life is very long. Since the number of load repetition can be known from the operation period of the facility, soundness against fatigue can be evaluated using an S-N curve. In this paper, a soundness evaluation method using an S-N curve for equipment supports subjected to machine vibrations is proposed.
\end{abstract}

\section{Background}

Long-term operation of nuclear power plants is a common issue for the countries that own them, and for that purpose it is essential to understand the soundness of the structures, systems, and components. In particular, since concrete structures in nuclear facilities are almost irreplaceable, their soundness evaluation becomes increasingly important as the operation period of the facilities grows longer. For this reason, the Architectural Institute of Japan published "Guidelines for Maintenance and Management of Structures in Nuclear Facilities" in 2008 (AIJ 2008) and revised these Guidelines in 2015 (AIJ 2015). In addition, in order to introduce the Guidelines overseas, the English version of the Guidelines will be released in 2021 (AIJ 2021).

The maintenance prescribed in the Guidelines can be divided into two categories: maintenance for checking current soundness and maintenance for evaluating long-term soundness. For checking current soundness of concrete structures in nuclear facilities, visual and non-destructive testing will be used to assess the degree of degradation phenomena. For maintaining soundness into the future, it is necessary to evaluate soundness based on degradation factors and mechanisms that cause

\footnotetext{
${ }^{1}$ Principal Engineer, Nuclear Power Department, Kajima Corporation, Tokyo, Japan.

*Corresponding author, E-mail: kontani@kajima.com

${ }^{2}$ General Manager, Power Generation Division, The Chugoku Electric Power Co., Hiroshima, Japan.

${ }^{3}$ Senior Manager, Civil \& Architectural Engineering Department, Nuclear Power Division, Chubu Electric Power Co., Inc., Nagoya, Japan.
}

degradation phenomena.

The degradation factors considered in the evaluation of long-term soundness of structures are heat (high temperature), irradiation, carbonation, chloride penetration, alkali silica reaction (ASR), and machine vibration. The ways of evaluating the soundness of structures are summarized in Table 1.

For heat and irradiation, threshold values are set for the soundness of structures. As long as the temperature or the fluence/dosage evaluated by analyses or measurement in the future are less than the threshold values, the structures are regarded as sound going into the future.

For carbonation and chloride penetration, the degradation mechanisms leading to the reinforcement corrosion are well understood, and we can evaluate the degree of degradation by measuring chloride content or carbonation depth using concrete samples.

Although the degradation mechanisms for ASR leading to concrete swelling and cracking are well understood, it is quite difficult to detect signs of degradation unless the degree of degradation is serious. The risk of ASR can be checked from records of the testing of aggregate alkali silica reactivity by a method such as the chemical method, mortar-bar method, or concrete bar method. Even after the detection of cracking and so on, it is possible to maintain the long-term soundness of a concrete structure by monitoring the progress of degradation phenomena because the progress rate of ASR is quite slow.

For machine vibration, the degradation state cannot be identified until cracks are visually detected as degradation phenomena, which is hardly ideal for the practical evaluation of long-term soundness. Therefore, we decided to carry out the present research on a soundness evaluation method for equipment supports, in cooperation with electric power companies. 
Table 1 Degradation factors and evaluation methods.

\begin{tabular}{|l|l|l|}
\hline \multicolumn{1}{|c|}{ Degradation factor } & \multicolumn{1}{|c|}{ Evaluation index } & \multicolumn{1}{c|}{ Evaluation criterion } \\
\hline \multirow{2}{*}{ Heat } & Concrete temperature & $\begin{array}{l}\text { Within } 65^{\circ} \mathrm{C} \text { for general parts } \\
\left.\text { Within } 90^{\circ} \mathrm{C} \text { for local parts (piping penetration, etc. }\right)\end{array}$ \\
\hline \multirow{2}{*}{$\begin{array}{l}\text { Heat } * \\
\text { Rhielding performance) }\end{array}$} & $\begin{array}{l}\text { Highest internal tempera- } \\
\text { ture }\end{array}$ & $\begin{array}{l}\text { Within } 88^{\circ} \mathrm{C} \text { for the heat due to neutrons } \\
\text { Within } 177^{\circ} \mathrm{C} \text { for the heat due to gamma rays }\end{array}$ \\
\cline { 2 - 3 } & Ambient temperature & $\begin{array}{l}\text { Within } 71^{\circ} \mathrm{C} \text { when the heat is due to neutrons } \\
\text { Within } 149^{\circ} \mathrm{C} \text { when the heat is due to gamma rays }\end{array}$ \\
\hline \multirow{2}{*}{ Carbonation } & Radiation exposure & $\begin{array}{l}1 \times 10^{20} \mathrm{n} / \mathrm{cm}^{2} \text { or less for neutron fluence } \\
2 \times 10^{8} \mathrm{~Gy}\left(2 \times 10^{10} \text { rad }\right) \text { or less for gamma ray dose }\end{array}$ \\
\hline \multirow{3}{*}{ Chloride penetration } & Carbonation depth & $\begin{array}{l}\text { During the in-service period, the carbonation depth has not increased so } \\
\text { much as to cause rebar corrosion. }\end{array}$ \\
\cline { 2 - 3 } & Corrosion amount & $\begin{array}{l}\text { The rebar corrosion amount has/hasn't reached the level for cracking to } \\
\text { occur. }\end{array}$ \\
\hline \multirow{2}{*}{ Alkali silica reaction } & Amount of chloride ions & $\begin{array}{l}\text { The amount of chloride ions at rebars has/hasn't reached the level for rebar } \\
\text { corrosion to occur. }\end{array}$ \\
\cline { 2 - 3 } & $\begin{array}{l}\text { Cracking } \\
\text { aggregate }\end{array}$ & Cracks due to ASR have/haven't been detected. \\
\hline Machine vibration & Cracking & $\begin{array}{l}\text { Records of the aggregate reactivity tests such as chemical method, mor- } \\
\text { tar-bar method, and concrete bar method, have been reviewed. }\end{array}$ \\
\hline
\end{tabular}

*: The temperature is checked for the shielding performance of the concrete structures and other factors are checked for structural safety.

\section{Design of anchor specimens}

\subsection{Tension loads}

According to "Design Recommendations for Various Composite Constructions," (AIJ 2010), the tensile force of a stud anchor due to concrete cone failure can be obtained by Equation (1), in which the angle of the cone is assumed to be $45^{\circ}$. The effects of the edge and spacing between anchors can be taken into account in evaluating the effective projected area of the cone failure surface.

$$
\mathrm{p}_{\mathrm{ta}}=k \cdot 0.31 \sqrt{\mathrm{F}_{\mathrm{c}}} \cdot \mathrm{A}_{\mathrm{c}}
$$

where $p_{\text {ta }}$ : Allowable tensile force per anchor bolt determined by concrete cone failure $\left(\mathrm{p}_{\mathrm{ta}}\right.$ is regarded as the tensile strength in this paper.).

$F_{c}$ : Design strength of concrete $\left(\mathrm{N} / \mathrm{mm}^{2}\right)$.

$0.31 \sqrt{F_{c}}$ : Tensile strength of concrete for concrete cone failure.

$\mathrm{A}_{\mathrm{c}}=\pi \cdot l_{e}\left(l_{e}+\mathrm{D}\right)$ : Horizontal projected area of cone failure surface (Fig. 1(a)). The horizontal projected area when multiple anchor bolts are installed in close proximity is determined according to Fig. 1(b). When anchor bolt(s) are close to the edge, the missing area is considered in calculating the horizontal projected area. $l_{e}$ : Effective embedment depth of anchor bolts in concrete.

d, D: Diameter of anchor bolt and anchor head.

$\mathrm{k}$ : Reduction factor for long-term and short-term allowable tensile load, For long-term allowable tensile load, $\mathrm{k}$ $=1 / 3$ according to AIJ (2010), and 0.3 according to JEAG (1991).

\subsection{Shear loads}

According to the Guidelines (AIJ 2010), the shear force of the stud anchor due to concrete failure can be obtained

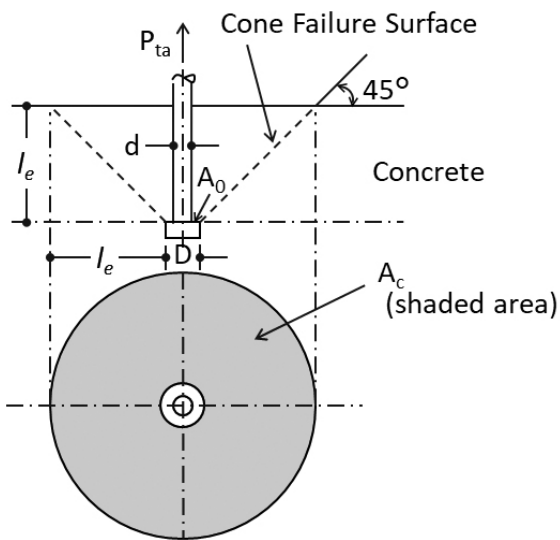

(a) Single anchor bolt

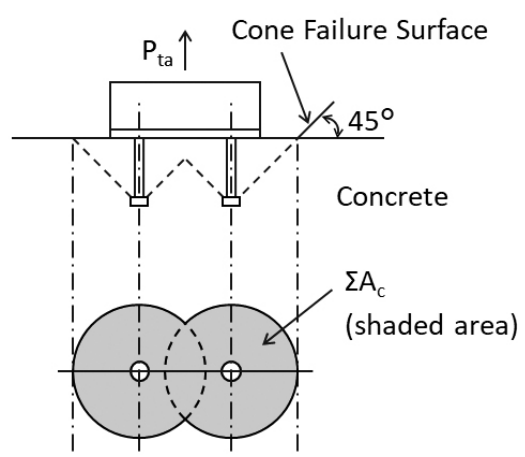

(b) Multiple anchor bolts

Fig. 1 Horizontal projected area of cone failure surface (AIJ 2010). 
by the smaller of the values calculated by Equations (2) and (3). The effective embedment depth $l_{\mathrm{e}}$ in Fig. $\mathbf{1}$ is evaluated longer by Equation (4) so that the tensile strength of the anchor is determined by the yield strength of the anchor bolt and that the concrete failure will not occur. The required effective embedment depth tends to be longer with decreasing distance from the center of the anchor bolt to the edge.

$$
\begin{aligned}
& \mathrm{p}_{\mathrm{sa} 1}=\mathrm{k} \cdot 0.5 \sqrt{\mathrm{F}_{\mathrm{c}} \cdot \mathrm{E}_{\mathrm{c}}} \cdot \mathrm{a}_{\mathrm{s}} \\
& \mathrm{p}_{\mathrm{sa} 2}=\mathrm{k} \cdot 0.31 \sqrt{\mathrm{F}_{\mathrm{c}}} \cdot \mathrm{A}_{\mathrm{qc}} \\
& \sigma_{\mathrm{s}} \cdot \mathrm{a}_{\mathrm{s}} \leq 0.31 \sqrt{\mathrm{F}_{\mathrm{c}}} \cdot \mathrm{A}_{\mathrm{c}}
\end{aligned}
$$

where $\mathrm{p}_{\mathrm{sa}}$ : Allowable shear force per anchor bolt due to concrete failure, the smaller of the forces obtained by Equation (2) for bearing failure of concrete by stud or Equation (3) for shear cone failure ( $\mathrm{p}_{\mathrm{sa}}$ is regarded as the shear strength in this paper.).

$\mathrm{F}_{\mathrm{c}}$ : Design strength of concrete $\left(\mathrm{N} / \mathrm{mm}^{2}\right)$.

$\mathrm{E}_{\mathrm{c}}$ : Young's modulus of concrete $\left(\mathrm{N} / \mathrm{mm}^{2}\right)$.

$0.5 \sqrt{\mathrm{F}_{\mathrm{c}} \cdot \mathrm{E}_{\mathrm{c}}}$ : Bearing strength of concrete.

$0.31 \sqrt{F_{c}}$ : Tensile strength of concrete for concrete cone failure.

$\mathrm{a}_{\mathrm{s}}$ : Axial ross-sectional area of stud anchor.

$\mathrm{A}_{\mathrm{qc}}=0.5 \cdot \pi \cdot \mathrm{c}^{2}$ : Vertical projected area of cone failure surface on the side surface in the direction of shear force (Fig. 2).

c: Distance from the center of the anchor bolt to the edge.

$\sigma_{\mathrm{s}}, \sigma_{\mathrm{y}}$ : Shear strength and yield strength of anchor bolt, and $\sigma_{\mathrm{s}}=0.7 \cdot \sigma_{\mathrm{y}}$.

$\mathrm{a}_{\mathrm{s}}$ : Sectional area of anchor bolt.

$\mathrm{k}$ : Reduction factor for long-term and short-term allowable tensile load, For long-term allowable tensile load, $\mathrm{k}$ $=1 / 3$ according to AIJ (2010), 0.3 for Equation (2), and 0.4 for Equation (3), according to JEAG (1991).

$\mathrm{A}_{\mathrm{c}}=\pi \cdot l_{e}\left(l_{e}+\mathrm{D}\right)$ : Horizontal projected area of cone failure surface (Fig. 1(a)).

$l_{e}$ : Effective embedment depth of anchor bolts in concrete.

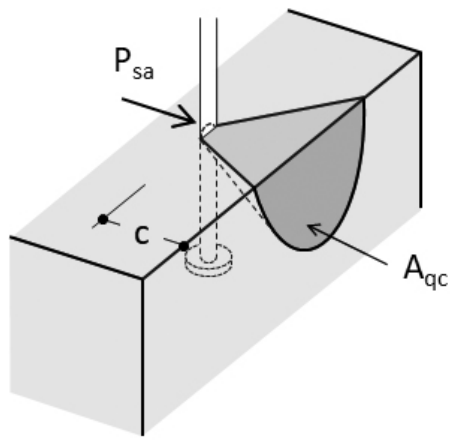

Fig. 2 Vertical projected area of the side (AIJ 2010).

\subsection{Combination of tension loads and shear loads}

According to the Guidelines (AIJ 2010), the combined force should be examined when tensile force $\mathrm{p}$ and shear force $\mathrm{q}$ act at the same time. The combined force per anchor bolt can be checked by Equation (5).

$$
\left\{\frac{\mathrm{p}}{\mathrm{p}_{\mathrm{ta}}}\right\}^{2}+\left\{\frac{\mathrm{q}}{\mathrm{p}_{\mathrm{sa}}}\right\}^{2} \leq 1
$$

where $\mathrm{p}_{\mathrm{ta}}, \mathrm{p}_{\mathrm{sa}}$ : Allowable tension force and shear force.

\section{Residual strength test after cyclic loading}

A summary of Kontani et al. (2016) is provided in this section for reference.

\subsection{Concrete cylinder specimens}

The authors performed residual strength tests after cyclic loading using plain concrete cylinder specimens $100 \mathrm{~mm}$ in diameter and $200 \mathrm{~mm}$ long to investigate whether or not cyclic loading reduces the strength and the rigidity of concrete in compression. The water-to-cement ratio was $59 \%$ and the compressive strength was $37.3 \mathrm{MPa}$ during the tests. The 37 specimens survived 316 to two million load cycles with speed of $5 \mathrm{~Hz}$ at the maximum stress ratios of $0.75,0.65,0.33$ and the minimum ratio of 0.05 of the static strength without cyclic loading.

The residual strength after cyclic loading were $1 \%$ to $9 \%$ higher than the static strength without cyclic loading. Figure 3 shows the relationship between compressive load and strain of two specimens. The curves of only representative cycles are shown for the cyclic loadings. Regarding deformation, the cylindrical specimen after two million load cycles with the maximum stress ratio 0.33 exhibited residual strain of around 250 micros, as can be seen in Fig. 3(b).

\subsection{Anchor specimens}

The authors also performed residual strength tests on the anchor specimens after cyclic loading to investigate the effects of cyclic loading on the strength and the rigidity of the anchor specimens. The details of the headed stud anchors and specimens are shown in Fig. 4. No reinforcement was placed in the area where cone failure was

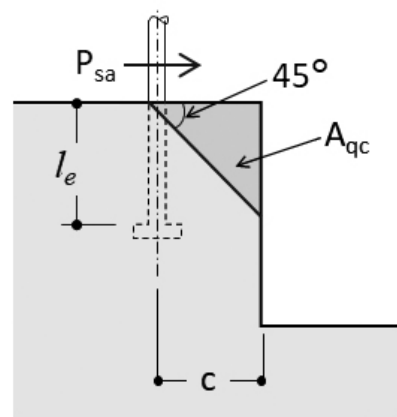


expected. The water-to-cement ratio was $60 \%$ and the compressive strength was $32-33 \mathrm{MPa}$ at the tests. The maximum stress ratios of cyclic loading were set at 0.75 , 0.65 , and 0.22 . The process of cyclic loading and the residual strength ratio after cyclic leading against the static test of the specimen are summarized in Fig. 5. The cyclic loading process is expressed by the arrow in the $\mathrm{X}$-direction and the residual anchor strength are shown by the arrow in the Y-direction. All the residual anchor strengths are equal to or greater (by up to $17 \%$ ) than the static strength of the specimen without cyclic loading. Increasing the number of load cycles increases the residual strength of the anchor specimen after cyclic loading.

Figures 6 and 7 show the test results of the anchor

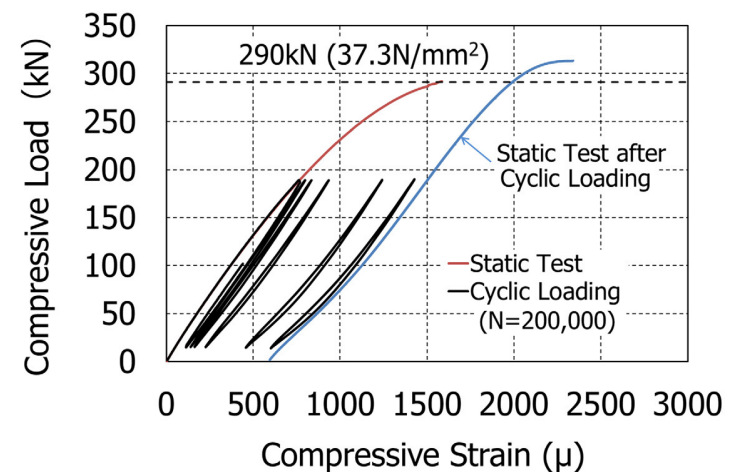

(a) CL-065-B-4 specimen with 10 million load cycles at the maximum stress ratio of 0.22 . Figure 6 shows the relationships between the tensile loads and pullout displacement of the anchor during fatigue loading as well as static loading with the results of the static test without cyclic loading. Figure 7 shows the relationship between pullout displacement of the anchor and the number of load cycles at the maximum and minimum stress ratios. In this case, no inelastic displacement was observed even after 10 million load cycles.

\subsection{Effect of cyclic loading on strength and stiffness}

The residual strength after cyclic loading was $1 \%$ to $9 \%$ higher than the static strength without cyclic loading for

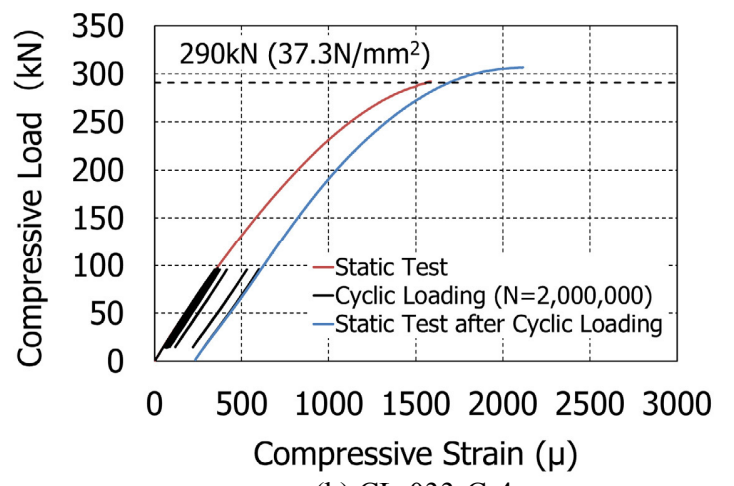

(b) CL-033-C-4

Fig. 3 Compressive load vs. strain from Kontani et al. (2016).
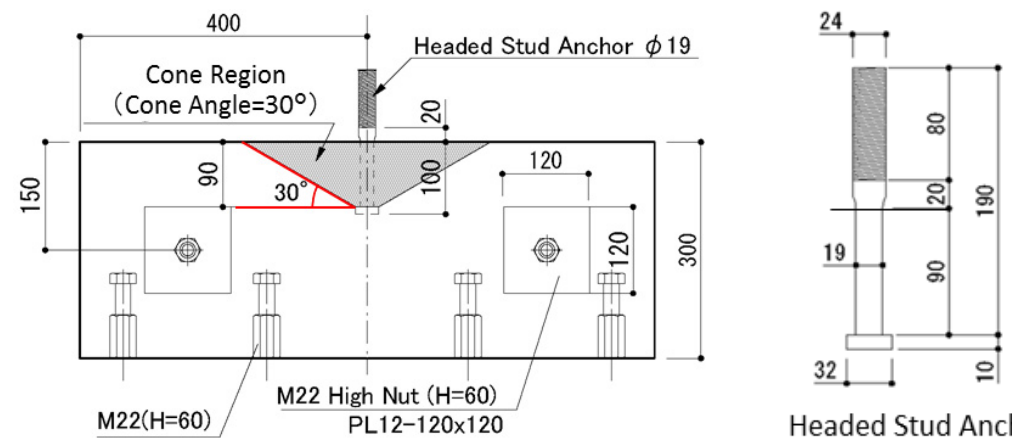

Fig. 4 Stud anchor specimen from Kontani et al. (2016).

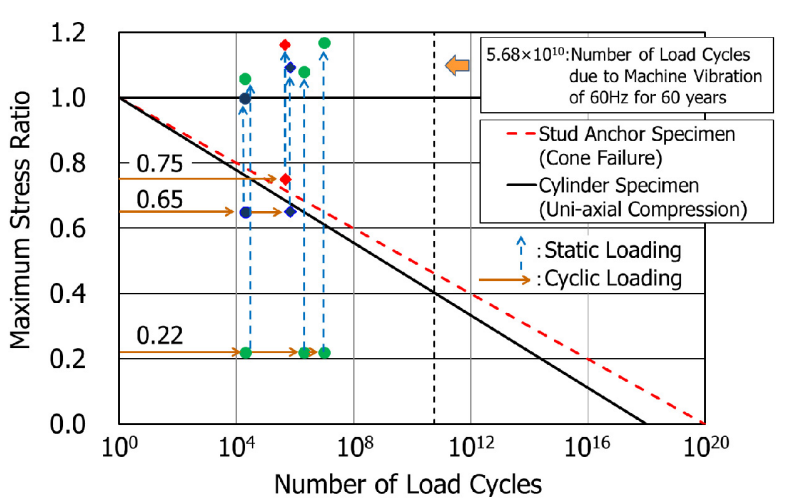

Fig. 5 Test results compared with S-N curves from Kontani et al. (2016).

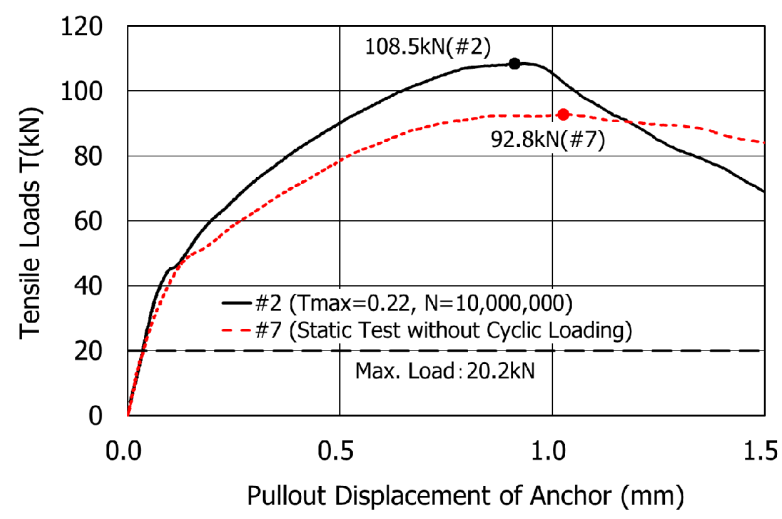

Fig. 6 Tensile loads vs. pullout displacement of anchor from Kontani et al. (2016). 
the concrete cylinder specimens in compression. The tendencies are consistent with previous studies such as Bennett and Muir (1967), Award and Hilsdorf (1974), and Bocca and Cwtti (2003).

Ballatore and Bocca (1997) stated that dynamic loading reduces pore space in the concrete so that in the subsequent static compressive tests deformability is hindered by improved material compaction, and that strain hardening takes place all the same as is reflected in an increase in maximum load and reduced deformability. Comparing Kontani et al. (2016) and Ballatore and Bocca (1997), both studies show similar strength increase of the cylindrical specimens, but different deformation behavior. Bocca and Cwtti (2003) stated that the test pieces subjected to preloading yielded more homogenous results, with a reduction in standard deviation, compared to non-preloaded test pieces probably because of a decrease in the stress peaks occurring in the material and a redistribution of stresses due to cyclic load induced creep.

The residual anchor strength after cyclic loading is equal to or greater than (by up to $17 \%$ ) the static strength of the specimen without cyclic loading according to Kontani et al. (2016). This phenomenon shows a tendency similar to the results of the compression tests on the cylinder specimens after cyclic loading. An explanation similar to that for the increase in residual cylinder strength after cyclic loading could be applied to the increase in the residual anchor strength after cyclic loading. Cracks on the cone surface develop by pulling of the stud anchor. The increase in anchor strength after cyclic

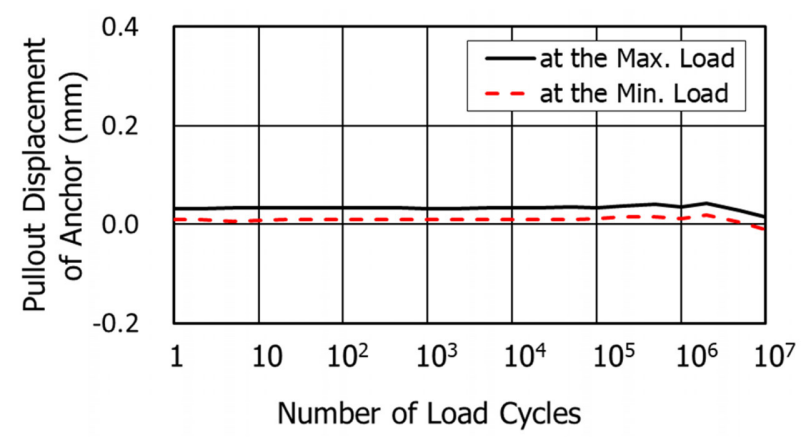

Fig. 7 Pullout displacement of anchor vs. number of load cycles from Kontani et al. (2016).

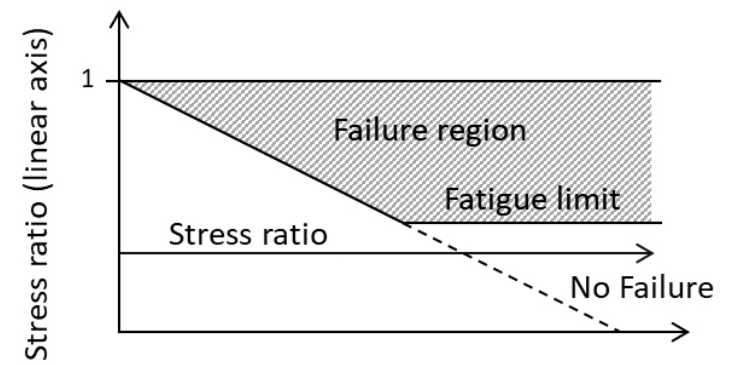

Number of load cycles (logarithmic axis)

(a)Steel loading is, according to Bocca and Cwtti (2003), due to the decrease in stress peaks in the material and at the crack tips, and the redistribution of stresses due to creep induced by cyclic loading.

According to the test results performed by Kontani et al. (2016), cyclic loading increased the residual strength of the anchor specimens in tension as well as the cylinder specimens in compression. Regarding deformation, the cylinder specimens exhibited residual strain of around 250 micros with the maximum stress ratio of 0.33 . On the other hand, no residual deformation was observed on the anchor specimens with the maximum stress ratio of 0.22 , which means that the effect of decreasing stress singularities due to cyclic loading induced creep which seemed to work very well even with the lower maximum stress ratios.

\section{Introduction of S-N curve}

The fatigue phenomenon can be expressed using S-N curves as shown in Fig. 8. The S-N curves show the relation between the maximum stress ratio (linear axis) and the number of constant load cycles (logarithmic axis). There is a fatigue limit identified for the steel member as shown in Fig. 8(a). Therefore, no matter how many cycles of stress at or below the fatigue limit are applied to a defect-free steel member, no fatigue fracture will occur. On the other hand, since no fatigue limit is identified for the concrete so far according to Stemland et al. (1990), Lee and Barr (2004), Tóth et al. (2016), and Karr et al. (2017), the linear relationship is extended to the stress ratio of zero, as shown in Fig. 8(b).

The idea introduced in this paper is to evaluate long-term soundness of equipment supports by S-N curves. Although the number of load cycles due to vibrating equipment such as turbines and generators is very high during normal operation of a nuclear power plant, the stress acting as the cyclic load is very low and is equal to or less than allowable stress, and thus it should be possible to evaluate the soundness of equipment supports by the S-N curve for operation periods such as 60 years.

The S-N curve can be expressed in Equation (6) according to Kishitani and Nishizawa (1987) and JSCE (2017). Transforming Equation (6) gives Equation (7).

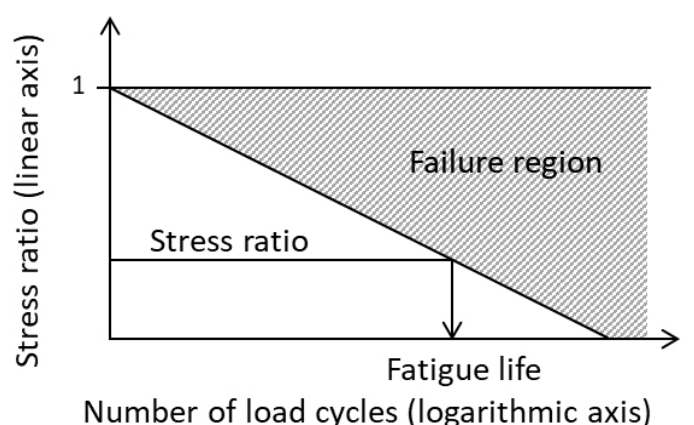

(b) Concrete

Fig. 8 Conceptual images of S-N curves (AIJ 2015). 
Table 2 S-N curves of previous research from Kishitani and Nishizawa (1987).

\begin{tabular}{|c|c|c|c|c|c|c|}
\hline $\begin{array}{l}\text { Specimen } \\
\text { shape }\end{array}$ & $\begin{array}{l}\text { Min. stress } \\
\text { ratio } \mathrm{S}_{\min } * 1\end{array}$ & $\begin{array}{l}\text { Max. stress } \\
\text { ratio } \mathrm{S}_{\max } * 1\end{array}$ & $\begin{array}{c}\mathrm{Y} \text {-axis } \\
\text { Intercept }{ }^{* 2}\end{array}$ & $\begin{array}{c}1 / \mathrm{K} \\
\text { in Eq.(7) }\end{array}$ & $\begin{array}{l}\mathrm{S}_{\max } \text { to fatigue } \\
\text { failure } *^{3}\end{array}$ & $\begin{array}{c}\mathrm{X} \text {-axis } \\
\text { intercept }\end{array}$ \\
\hline prism & 5 & $65-85$ & 1.025 & -6.369 & 62.4 & 16.1 \\
\hline prism & 10 & $65-80$ & 1.000 & -5.495 & 65.4 & 18.2 \\
\hline cylinder & 2 & $66-84$ & 0.958 & -4.673 & 66.3 & 20.5 \\
\hline prism & $14-22$ & $53-100$ & 0.927 & -4.292 & 65.7 & 21.6 \\
\hline cylinder & 8.6 & $65-80$ & 1.016 & -5.236 & 68.3 & 19.4 \\
\hline cylinder & 10.3 & $59-74$ & 0.929 & -5.051 & 61.1 & 18.4 \\
\hline & & & & average & 64.9 & 19.0 \\
\hline
\end{tabular}

$* 1:$ In $\%$ to static strength

*2: $1+\frac{\log \mathrm{N}}{\mathrm{K}} \cdot \mathrm{S}_{\min }$ in Equation (7)

$* 3$ : The maximum stress ratio to fatigue failure at $2 \times 10^{6}$ load cycles in $\%$ of static strength

Equation (7) shows that increasing $\mathrm{S}_{\min }$ increases fatigue life, as experimentally demonstrated by Stemland et al. (1990). Therefore, if $S_{\min }$ is assumed to be zero, the fatigue life can be lowered against the same maximum stress ratio, which will provide more conservative evaluation.

Kishitani and Nishizawa (1987) reviewed the fatigue tests on concrete cylinder or prism specimens and evaluated S-N curves in the form of Equation (7) as shown in Table 2. As can be seen, all curves but one will not intercept one on the Y-axis because each curve was evaluated to fit each set of experimental data. The situation does not seem appropriate for generalization of the $\mathrm{S}-\mathrm{N}$ curve. Therefore, by setting zero to $\mathrm{S}_{\min }$, Equation (7) is simplified to Equation (8), which intercepts one on the Y-axis of the S-N curve.

Next, it is necessary to determine the constant $\mathrm{K}$, which means the intercepting point on the X-axis. According to Table 2, the maximum stress ratio to fatigue failure at $2 \times 10^{6}$ load cycles is $65 \%$ of static strength, which gives 18 as constant $\mathrm{K}$ to provide Equation (9) for the compression fatigue of concrete specimens. The S-N curve of the anchor specimen can be found in Eligehausen, et al. (2006) and is expressed in Equation (10). The S-N curve for concrete can be found in JSCE (2017) and is expressed in Equation (11) with the lower stress ratio of zero. The reduction factor of 0.85 is introduced to account for long-term strength and so on. Equations (9), (10), and (11) are shown in Fig. 9.

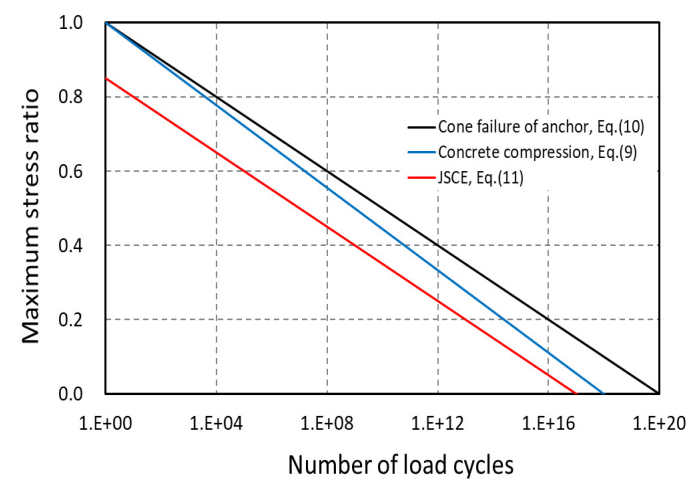

Fig. 9 Various S-N curves.

$$
\begin{aligned}
& \log \mathrm{N}=\mathrm{K} \cdot \frac{1-\mathrm{S}_{\text {max }}}{1-\mathrm{S}_{\text {min }}} \\
& \mathrm{S}_{\text {max }}=\left(1+\frac{\log \mathrm{N}}{\mathrm{K}} \cdot \mathrm{S}_{\min }\right)-\frac{\log \mathrm{N}}{\mathrm{K}} \\
& \mathrm{S}_{\text {max }}=1-\frac{\log \mathrm{N}}{\mathrm{K}} \\
& \mathrm{S}_{\text {max }}=1-\frac{\log \mathrm{N}}{18} \\
& \mathrm{~S}_{\text {max }}=1-\frac{\log \mathrm{N}}{20} \\
& \mathrm{~S}_{\text {max }}=0.85 \times\left(1-\frac{\log \mathrm{N}}{17}\right)
\end{aligned}
$$

where $\mathrm{S}_{\max }, \mathrm{S}_{\min }$ : Maximum and minimum stress ratio to static strength.

$\mathrm{N}$ : Number of load cycles to fatigue failure.

$\mathrm{K}$ : Constant.

\section{Proposal of soundness evaluation method for equipment support}

\subsection{Introduction of S-N curve of plain concrete in compression}

The number of fatigue data for the anchor specimens is very small compared with fatigue data of concrete specimens in compression. At the same maximum stress ratio, the S-N curve for the anchor specimens expressed by Equation (10) provides greater fatigue life than that for concrete specimens in compression by Equation (9). Moreover, the reduction factor of 0.85 is introduced to Equation (10) and its $\mathrm{X}$ intercept is reduced from 18 to 17 to yield Equation (11) for conservativeness in fatigue evaluation. In this paper, the soundness evaluation using Equation (11) is proposed because Equation (11) derived by JSCE (2016) is based on the investigation of the enormous body of test data, which is believed to increase reliability, and because Equation (11) provide shorter and 
more conservative fatigue life than Equation (9).

Although the failure mode of the anchor specimens is very different from the concrete cylinder specimens in compression, the progress of fatigue cracking of the anchor specimens is more stable and slower than that of the cylindrical specimens in compression. Thus, because Equation (11) is reliable in terms of the amount of data considered and provides shorter and more conservative fatigue life than Equation (9), it is proposed for the soundness evaluation of equipment supports in this paper to employ Equation (11) for cylinder specimens in compression instead of Equation (9) for anchor specimens although the fatigue process might be a little faster in cylinder specimens in compression.

As shown in Fig. 5, the residual strength of the anchor tends to increase with larger numbers of load cycles even if the maximum stress level is low. In the proposed evaluation method, since the fatigue limit ratio is set to the constant value of 0.3 , the fatigue limit load tends to increase.

As shown in Fig. 6, no residual deformation is observed in the equipment support even after 10 million load cycles. As shown in Fig. 7, pull-out displacement of the anchor specimen is constant at the maximum stress level and does not increase up to 10 million load cycles.

Ozbolt et al. (1999) and Eligehausen and Sawade (1989) observed that cracking started at about $25 \%$ of peak load from a series of tensile test results on anchor specimens and that crack growth was very stable even after cracking at the anchor head. This might be a reason why no residual deformation was observed and the deformation at the maximum stress level was constant up to 10 million cycles, as shown in Figs. 6 and 7.

The knowledge of the strength increase after cyclic loading, and of no residual deformation and constant deformation at the maximum stress level up to 10 million load cycles, as shown in Figs. 5 to 7, is not directly incorporated in the proposed evaluation method. However, it improves the understanding of anchor behaviors under different numbers of load cycles and shows the validity to the soundness evaluation.

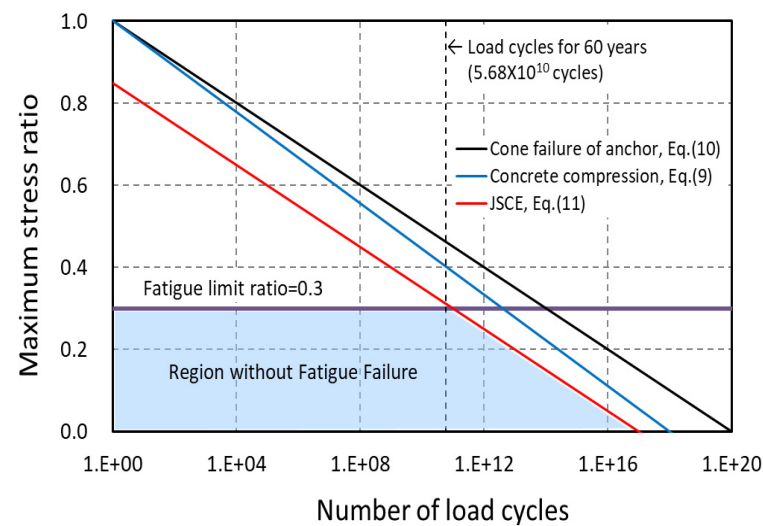

Fig. 10 Safe region without fatigue failure (The reference strength to maximum stress ratio is the static strength, $\mathrm{p}_{\mathrm{a}}$, obtained by experiment, and the fatigue limit ratio is 0.3 .).

\subsection{Introduction of region without fatigue failure in S-N curve}

According to JEAG (1991), the reduction coefficient for long-term allowable stress is 0.3 of the static strength. This means that the stresses acting on an equipment support are equal to or less than 0.3 of static strength during normal operation of the nuclear facility. The S-N curve expressed by Equation (11) is proposed for use for soundness evaluation.

The number of load cycles to be considered for each rotating machine can be obtained. In Japan, nuclear power plants can be operated for up to 60 years if a 20 -year extension of the operating period is approved, so the target is 60 years. For example, turbine and generator that rotate at $1,800 \mathrm{rpm}$ in the $60 \mathrm{~Hz}$ region in Japan will generate load cycles of $5.68 \times 10^{10}$ for 60 years. The S-N curves and the number of load cycles for the turbine and generator are shown in Fig.10. The shaded area is the region without anchor fatigue failure. As long as the cyclic loads acting on the equipment supports are within this region, no fatigue failure will occur before the operation period exceeds 60 years.

The equipment supports of rotating machines other than turbines and generators could be also evaluated by checking the number of load cycles expected during their lifetime with the proposed S-N curve. As long as the number of load cycles and the maximum stress ratio is within the shaded area in Fig. 10, the equipment supports can be regarded as sound for their lifetime.

\section{Discussion}

\subsection{Fatigue limit to expected load cycles}

The intersection of the S-N curve and the X-axis indicates the fatigue fracture of a concrete specimen or member. In reality, however, the fracture does not occur because the stress ratio is zero. Thus, it is considered that concrete also should have a fatigue limit although the stress ratio could be quite low for infinite load cycles. For conventional fatigue testing with loading frequency of 10 $\mathrm{Hz}$, the fatigue data of concrete are available up to $1.5 \times 10^{7}$ cycles with the maximum stress ratio down to 0.60 in Lantsoght et al. (2016). Ultrasonic fatigue testing has been employed to obtain the fatigue properties of metals. The number of load cycles reached more than $2 \times 10^{10}$ and the fatigue limits of some metals could be reevaluated according to Mayer (2016). Karr et al. (2017) introduced the ultrasonic fatigue test to concrete and the concrete specimens survived $2 \times 10^{9}$ cycles with stress ratio of 0.38 and loading frequency of around 20 $\mathrm{kHz}$. Even with the ultrasonic fatigue test results for an enormous number of loading cycles, no clues regarding the fatigue limit of concrete were obtained, which is consistent with Stemland et al. (1990), Lee and Barr (2004) and Tóth et al. (2016). Since the experimental determination of concrete fatigue properties is very time consuming, it is considered reasonable to evaluate soundness by the S-N curve with a straight line. 
Equation (11) was compared with the fib model code ( $i b$ 2010) to validate the proposed method. Equation (11) is shown in Fig. 11 with S-N curves obtained from the fib model code with the minimum stress ratios of 0 and 0.2 . The S-N curves have a concave shape. In the region where load cycles are more than $10^{9}$, Equation (11) provides more conservative fatigue life than the fib model code.

Stemland et al. (1990) performed the constant amplitude tests on concrete specimens and the test results showed that the fatigue life at lower $\mathrm{S}_{\max }$ values tends to be longer than indicated by the linear relationship. They proposed a design formula to predict the relation between $\mathrm{S}_{\max }, \mathrm{S}_{\min }$, and $\mathrm{N}$ as shown in Equation (12), which can be transformed into Equation (13). The design formula is illustrated in Fig. 12 with $\mathrm{S}_{\min }=0$ for Equation (13). The effect of the change in minimum stress ratio on the fatigue life were incorporated in the design formula. As can be seen in Fig. 12, the slope of the curve changes at $\log \mathrm{N}$ $=6$. It was also proposed that $\log \mathrm{N}$ greater than $\log \mathrm{N}=6$ should be multiplied by some reduction factor.

$$
\begin{aligned}
& \log \mathrm{N}=\left(12+16 \cdot \mathrm{S}_{\text {min }}+8 \cdot \mathrm{S}_{\text {min }}^{2}\right) \cdot\left(1-\mathrm{S}_{\text {max }}\right) \\
& \mathrm{S}_{\text {max }}=1-\frac{\log \mathrm{N}}{\left(12+16 \cdot \mathrm{S}_{\min }+8 \cdot \mathrm{S}_{\min }^{2}\right)}
\end{aligned}
$$

Tóth et al. (2016) proposed a fatigue model to predict fatigue life of undercut anchors even at very high numbers of load cycles. The model was proposed based on

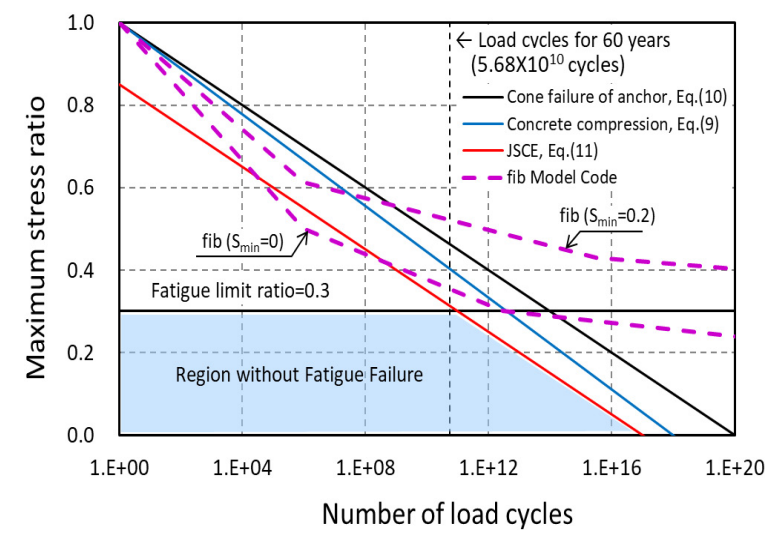

Fig. 11 Comparison with fib model code.

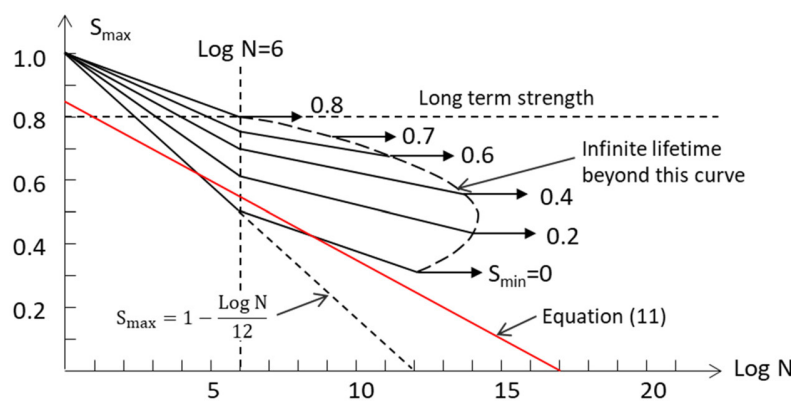

Fig. 12 Schematic S-N diagram for fatigue of concrete in compression with fatigue limit according to Stemland et al. (1990). the Paris law, test results, and analysis results. The model uses the energy dissipation that causes material degradation due to repeated loading, not the stress intensity factor in the Paris law. The model predicted the fatigue life very well and decreased the slope of the S-N curve with increasing load cycles at a very high number of load cycles. Tóth et al. (2016) also stated that no endurance limit can be observed, which corresponds to the expected concrete fatigue behavior.

According to Stemland et al. (1990), a fatigue limit does not exist from a fracture mechanic point of view because all stress variations contribute to the damage and failure is only a question of time. It should, however, be possible to speak about a fatigue limit for practical design, since most structures are exposed to a limited number of cycles during their lifetime. The S-N curves with fatigue limits at different minimum stress ratios are shown in Fig. 12 with Equation (11).

According to the above discussion, it would be possible to define a fatigue limit ratio with a limited number of load cycles of nuclear facilities. The fatigue limit ratio of the turbine and generator for load cycles of $5.68 \times 10^{10}$ for 60 years can be defined as 0.3 of the reference strength to maximum stress ratio.

\subsection{Effective embedment depth ratio for shear load}

Pallarés (2010) investigated the test data in shear in terms of an effective embedment depth ratio le/d. For the shear tests with normal weight concrete, more than $84 \%$ of the specimens failed in steel in the tests with embedment ratios of 4.5 and above, and more than $98 \%$ failed in steel with embedment ratios of 5.5 and above. According to Matsuzaki et al. (1984), the shear strength of the stud anchor with the effective embedment depth ratio of 5.0 and above is determined by the failure in steel not in concrete.

For example, the embedment depth ratio is evaluated to satisfy Equation (4) with concrete strength and Young's modulus of $30 \mathrm{MPa}$ and $25 \mathrm{kN} / \mathrm{mm}^{2}$, bolt yield strength of $215 \mathrm{~N} / \mathrm{mm}^{2}$, and diameters of anchor bolt and anchor head of $22 \mathrm{~mm}$ and $35 \mathrm{~mm}$, respectively. The minimum embedment depth ratio for concrete failure is 4.2, which is consistent with Pallarés (2010) and Matsuzaki et al. (1984). With the above conditions, it is confirmed that the allowable shear force psal evaluated by Equation (1) is much greater than psa 2 evaluated by Equation (2). For shear load, only Equation (3) needs to be considered as long as the embedment depth satisfies Equation (4).

\subsection{Comparison between S-N curve and previ- ous test data}

Equation (11) is compared with fatigue test results collected by Lantsoght et al. (2016) in Fig. 13. The data with compressive strength of $100 \mathrm{MPa}$ or less and lower stress ratio of 0.3 or less were selected to validate the conservativeness of Equation (11). The number of data 
was 191 and the maximum number of load cycles was 12 million. As can be seen from Fig. 13, Equation (11) provides safe evaluation for the entire data.

Equation (11) is compared with the ultrasonic fatigue test results performed by Karr et al. (2017) in Fig. 13. The maximum number of load cycles is $2.6 \times 10^{9}$, which can never be reached in a conventional fatigue test. Fatigue test data and fitting curves of two series of specimens with strength of $80 \mathrm{MPa}$ and $107 \mathrm{MPa}$ are plotted in Fig. 13. The fatigue life obtained from the ultrasonic tests was apparently smaller than that from Equation (9), which is kind of an averaged S-N curve. The reason for this could be the shape of the specimen tested. Specimens $21 \mathrm{~mm}$ in diameter and $151 \mathrm{~mm}$ in length with steel rods connected at both ends were employed in order to cause resonance. The specimens were obtained from the concrete block. These might be the reasons for the shorter fatigue life. However, Equation (11) provides a fair evaluation to the ultrasonic fatigue data as well.

\subsection{Determination of reference strength to maximum stress ratio}

So far, the maximum stress ratio is defined relative to the static strength of the anchor specimens. The fatigue limit ratio is set at 0.3 as shown in Fig. 10. As long as the static strength is obtained by the experiments of the anchor specimens, the conditions described in Fig. 10 are valid.

There are many test data on the static strength of the anchor specimens considering the edge effect and multiple anchor effect. According to AIJ (2010), two thirds of the cone failure strength $\mathrm{p}_{\mathrm{ta}}$ from Equation (1) almost corresponds to the lower limit of the experimental data collected. Two thirds of the shear strength $\mathrm{p}_{\mathrm{sa}}$ from Equation (3) also corresponds to the lower limit of the experimental data collected. The static strength of the anchors of existing equipment supports of nuclear facilities cannot be obtained by experiment and should be evaluated by the equations from AIJ (2010). Thus, the maximum stress ratio should be defined by two thirds of the static strength, $(2 / 3) \cdot \mathrm{p}_{a}$, evaluated by the equations from AIJ (2010) for conservative evaluation, as described in Fig. 14.

This discussion is extremely important for defining the S-N curve. As shown in Equation (14), the reference

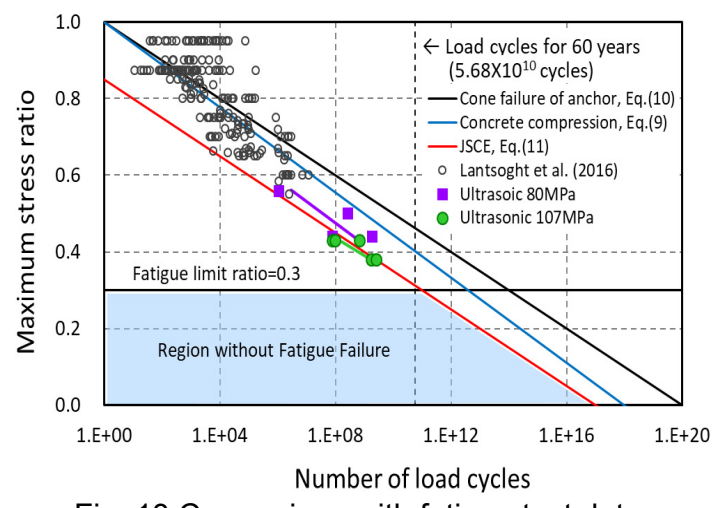

Fig. 13 Comparison with fatigue test data. strength to maximum stress ratio should be defined by two thirds of the static strength, $(2 / 3) \cdot \mathrm{p}_{a}$, from AIJ (2010) for conservative evaluation instead of the static strength of $\mathrm{p}_{a}$. As a result, the fatigue limit load is $0.2 \cdot \mathrm{p}_{a}$, as shown in Equation (15). However, the fatigue limit ratio to the reference strength is the same as 0.3 .

The static strength of equipment supports of turbines and generators is evaluated by the equations from AJI (2010), and two thirds of the static strength, $(2 / 3) \cdot \mathrm{p}_{a}$, is the reference strength to maximum stress ratio. The long-term design load acting on equipment supports can be obtained from the design process due to rotation force and vibration amplitude of rotating machine. If the long-term design load acting on the equipment support is less than the fatigue limit load of $0.2 \cdot \mathrm{p}_{a}$, the equipment support can be considered to be sound for 60 years of operation.

The combined force of the anchor bolt can be checked by Equation (16), which is the same formula with a different constant on the right side of the equation. The constant is the square of the fatigue limit ratio, which is 0.04 for the soundness evaluation of equipment supports. If the tensile load $\mathrm{p}$ and the shear load $\mathrm{q}$ acting on the equipment support are less than the fatigue limit and if $p$ and q satisfy Equation (16), the support can be regarded sound for 60 years.

$$
\begin{aligned}
& \text { Reference strength to } \\
& \text { maximum stress ratio }=(2 / 3) \cdot \mathrm{p}_{a} \\
& \text { Fatigue limit load }=0.3 \times(2 / 3) \cdot \mathrm{p}_{a}=0.2 \cdot \mathrm{p}_{a} \\
& \left\{\frac{\mathrm{p}}{\mathrm{p}_{\mathrm{ta}}}\right\}^{2}+\left\{\frac{\mathrm{q}}{\mathrm{p}_{\mathrm{sa}}}\right\}^{2} \leq(\text { fatigue limit ratio })^{2}=0.04
\end{aligned}
$$

where $\mathrm{p}_{a}$ : Allowable force of $\mathrm{p}_{\mathrm{ta}}$ or $\mathrm{p}_{\mathrm{sa}}$ according to AIJ (2010).

$\mathrm{p}_{\mathrm{ta}}, \mathrm{p}_{\mathrm{sa}}$ : Allowable tension force from Equation (1) and shear force from Equation (3) with reduction factor $\mathrm{k}=1$.

\subsection{Further development of soundness evalua- tion methods}

Equation (11) with the maximum stress ratio of 0.3 yields the fatigue life of $10^{11}$, which corresponds to 106 years of operation for the turbine and generator in the 60 $\mathrm{Hz}$ region in Japan. Therefore, the proposed evaluation method can be applied to up to 100 years of operation, beyond the 80 years designated by the subsequent license renewal (NUREG 2017) in the United States. In addition, the proposed method can be applied to load cycles longer than 100 years if the maximum stress ratio is reduced so that it is within the shaded area in Fig. 10.

The proposed method can also be applied to other types of anchors than stud anchors by collecting experimental results and analyzing them.

On the other hand, if the stress ratio is increased over 0.3 , residual deformation and stiffness reduction might 
occur in equipment supports due to load cycles. It is necessary, in this case, to confirm by experiment that there is no problem if the stress ratio exceeds 0.3 .

\section{Conclusions}

A soundness evaluation method for equipment supports consisting of anchors using the S-N curve of plain concrete specimens in compression is proposed. If the static strength is obtained by experiment, the reference strength can be the static strength and the fatigue limit ratio is 0.3 , as shown in Fig. 10.

If the static strength is evaluated by the equations from AJI (2010), the reference strength should be two thirds of the static strength, $(2 / 3) \cdot \mathrm{P}_{a}$, and the fatigue limit load is $0.2 \cdot \mathrm{P}_{a}$, however, the fatigue limit ratio remains 0.3 as shown in Fig. 14. For the soundness evaluation of existing equipment supports, the strengths of the equipment supports can be evaluated by the equations from AJI (2010) and cannot be obtained by experiment, therefore, the conditions described in Fig. 14 should be applied.

The static strength of the equipment supports of turbines and generators is evaluated by the equations from AJI (2010) and two thirds of the static strength, $(2 / 3) \cdot \mathrm{P}_{a}$, is the reference strength to maximum stress ratio. The long-term design load acting on equipment supports can be obtained from the design process due to the rotation force and vibration amplitude of the rotating machine. If the long-term design load acting on an equipment support is less than the fatigue limit load of $0.2 \cdot \mathrm{P}_{a}$, the equipment support can be regarded sound for 60 years of operation.

The equipment supports of rotating machines other than turbines and generators could be also evaluated by checking the number of load cycles expected during their lifetime with the proposed S-N curve. As long as the number of load cycles and maximum stress ratio are within the shaded area in Fig. 14, the equipment supports can be regarded sound for their lifetime.

According to AIJ (2015), the degradation state of equipment supports cannot be identified until cracks are visually detected as degradation phenomena for machine vibration. As a remedy, the method proposed in this paper allows the long-term soundness evaluation of equipment supports in a practical manner, which will increase the reliability of the machines. The proposed method will be reflected to "AIJ Guidelines for Maintenance and Management of Structures in Nuclear Facilities," in the next revision.

\section{Acknowledgements}

This study was carried out as part of collaborative research by Chubu Electric Power Co., Inc., Hokkaido Electric Power Co., Inc., Tohoku Electric Power Co., Inc., Tokyo Electric Power Company Holdings, Inc., Hokuriku Electric Power Co., Inc., Kansai Electric Power Co., Inc., Chugoku Electric Power Co., Inc., Shikoku Electric Power Co., Inc., Kyushu Electric Power Co., Inc., The Japan Atomic Power Company, Electric Power Development Co., Ltd. and Japan Nuclear Fuel Limited. We sincerely thank Professor Emeritus Katsuki Takiguchi of Tokyo Institute of Technology, Dr. Hideo Kasami, Professor Shigemitsu Hatanaka of Mie University, Professor Ichizo Kishimoto of Kinki University and Professor Ippei Maruyama of Nagoya University, for their advice regarding the implementation of this study.

\section{References}

AIJ, (2015). "Guidelines for maintenance and management of structures in nuclear facilities." Tokyo: Architectural Institute of Japan. (in Japanese)

AIJ, (2010). "Design recommendations for various composite constructions." Tokyo: Architectural Institute of Japan. (in Japanese)

AIJ, (2021). "AIJ Guidelines for maintenance and management of structures in nuclear facilities." Tokyo: Architectural Institute of Japan.

Award, M. E. and Hilsdorf, H. K., (1974). "Strength and deformation characteristics of plain concrete subjected

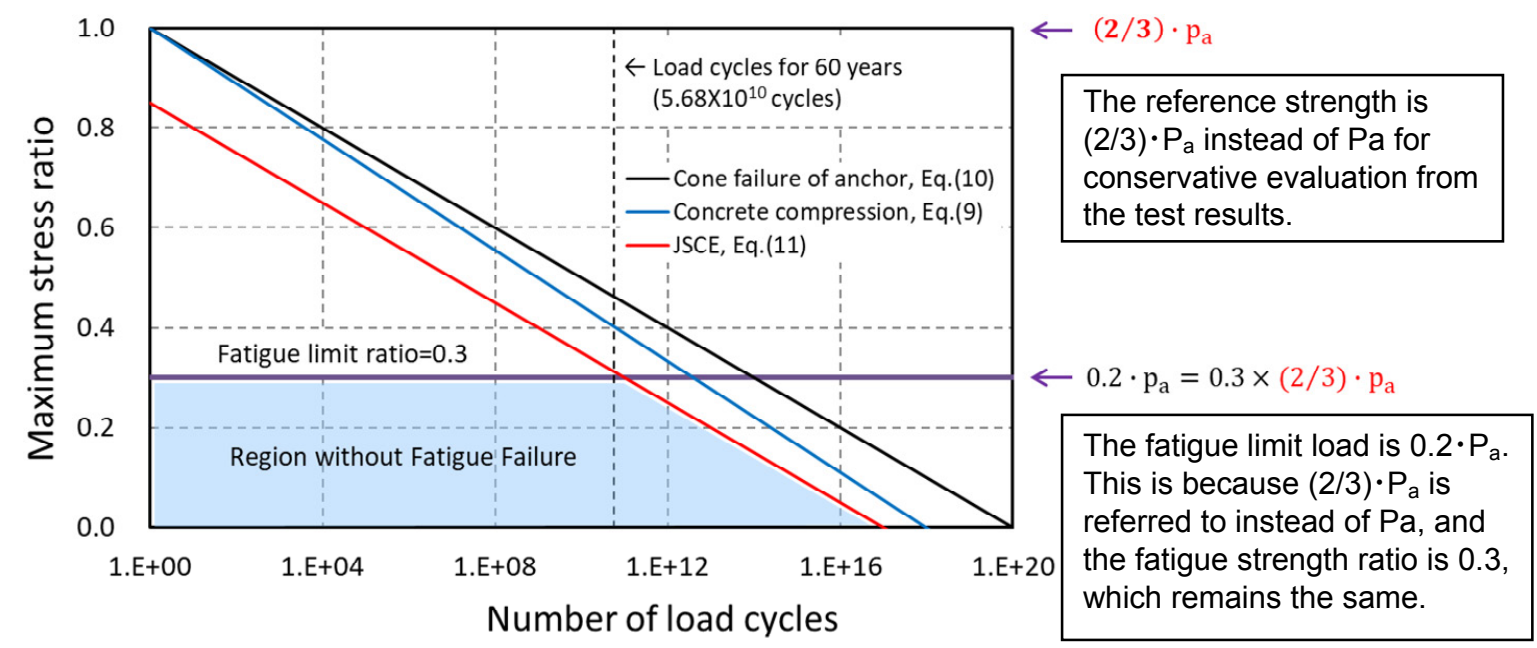

Fig. 14 Safe region without fatigue failure (The reference strength to maximum stress ratio is two thirds of the static strength, $(2 / 3) \cdot p_{a}$, evaluated by the equations from AIJ (2010), fatigue limit load is $0.2 \cdot p_{a}$ and fatigue limit ratio remains 0.3 ). 
to high repeated and sustained loads." Abeles Symposium Fatigue of Concrete, ACI SP-41-1, 1-14, 1974.

Ballatore, E. and Bocca, P., (1997). "Variations in mechanical properties of concrete subjected to low cycle loads." Cement and Concrete Research, 27(3), 453-462.

Bennet, E. W. and Muir, S. E. St J., (1967). "Some fatigue tests of high-strength concrete in axial compression." Magazine Concrete Research, 19, 113-117.

Bocca, P. and Cwtti, M., (2003). "Variations in mechanical properties and temperature of concrete subjected to low cycle loads, including high loads." Materials and Structures, 36(Jan.-Feb.), 40-45.

Eligehausen, R. and Sawade, G., (1989). "A fracture mechanics based description of the pull-out behavior of headed studs embedded in concrete." In: L. Elfgren Ed. Fracture mechanics of concrete structures (RILEM Report 3). London: Chapman and Hall, 281-299.

Eligehausen, R., Mallée, R. and Silva, J. F., (2006). "Anchorage in concrete construction." Berlin: Ernst \& Sohn.

Lantsoght, E. O. L., Van der Veen, C. and De Boer, A., (2016). "Proposal for the fatigue strength of concrete under cycles of compression." Construction and Building Materials, 107, 138-156.

JEAG, (1991). "Technical guidelines for aseismic design of nuclear power plants, supplement, (JEAG4601-1991)." The Japan Electric Association.

fib, (2010). "fib Model code 2010." International Federation for Structural Concrete.

JSCE, (2017). "Standard specifications for concrete structures-2017, Design." Japan Society of Civil Engineers. (in Japanese)

Karr, U., Schuller, R., Fitzka, M., Denk, A., Strauss, A. and Mayer, H., (2017). "Very high cycle fatigue testing of concrete using ultrasonic cycling." Materials Testing, 59(5), 438-444.

Kishitani, K. and Nishizawa, N., (1987). "Fatigue -Durability series of concrete structures-." Tokyo:
Gihodo Shuppan Co. Ltd. (in Japanese)

Kontani, O., Ishitobi, N., Kawada, J., Taogoshi, N., Koge, M, and Umeki, Y., (2016) "Residual static strength of concrete cylinder specimen and stud anchor specimen after cyclic loadings." Journal of Advanced Concrete Technology, 14, 634-642.

Lee, M. K. and Barr, B. I. G., (2004). "An overview of the fatigue behaviour of plain and fibre reinforced concrete." Cement \& Concrete Composites, 26, 299-305.

Matsuzaki, I., (1984). "Strength of anchor bolts fixed to concrete members." Concrete Journal, Japan Concrete Institute, 22(7), 54-61. (in Japanese)

Mayer, H., (2016). "Recent developments in ultrasonic fatigue." Fatigue \& Fracture of Engineering, Materials and Structures, 39, 3-29.

NUREG, (2017). "Generic aging lessons learned for subsequent license renewal (GALL-SLR) (Report NUREG-2191)." United States Nuclear Regulatory Commission, (1\&2).

Ozbolt, J., Eligehausen, R. and Reinhardt, H. W., (1999), "Size effect on the concrete cone pull-out load," International Journal of Fracture, 95, 391-404.

Pallarés, L. and Hajjar, J. F., (2010). "Headed steel stud anchors in composite structures, Part I: Shear," Journal of Constructional Steel Research, 66, 198-212.

Stemland H., Petkovic G., Rosseland S. and Lenschow R., (1990). "Fatigue of high strength concrete." Nordic Concrete Research, 90, 172-196.

Tóth, M., Ožbolt, J., Fuchs, W. and Hofmann, J., (2016). "Fatigue behavior of fasteners in case of concrete failure: Numerical and experimental investigations." In: Proc. of fib Symposium on Performance-based Approaches for Concrete Structures, 21-23 November, Cape Town.

Thun, H., (2006). "Assessment of fatigue resistance and strength in existing concrete structures." Thesis ( $\mathrm{PhD})$. Department of Civil \& Environmental Engineering, Luleå University of Technology. 


\section{Appendix : Fatigue of reinforced concrete struc- ture}

The reduction factors of concrete material or structural members are proposed based on a number of test results subjected to stepwise increases of cyclic loading level simulating an earthquake. For short-term allowable load for equipment supports, the reduction factors of Equation (1) are 2/3 and 0.6 according to AIJ (2010) and JEAG (1991), respectively. In the case where the in-plane shear strain due to earthquakes is significantly large in a reinforced concrete wall, reduction factors corresponding to shear strains have been introduced for the design of supports for equipment and piping as shown in Fig. 15, according to JEAG (1991). In this way, the effects of low cycle fatigue due to earthquakes are considered in designing structures.

The strength reduction due to high cycle fatigue is considered in designing structures such as reinforced concrete girders subjected to repeated loading and reinforced concrete slabs under moving wheel load according to JSCE (2017). The fatigue strength of concrete is evaluated using Equation (6) for load cycles of $2 \times 10^{6}$ or less and the Miner's law is applied for variations in the maximum stress ratio.

The proposed evaluation method in this paper deals with the soundness evaluation of existing equipment supports under ultra-high cycle fatigue. The same concept is not applied to designing equipment supports at this time. The load cycles due to machine vibration are on the order of ten to the tenth power with constant amplitude. The soundness of the equipment support is evaluated by extrapolating to the tenth power order using Equation (11), which is derived by removing the term of the minimum stress ratio from Equation (6).

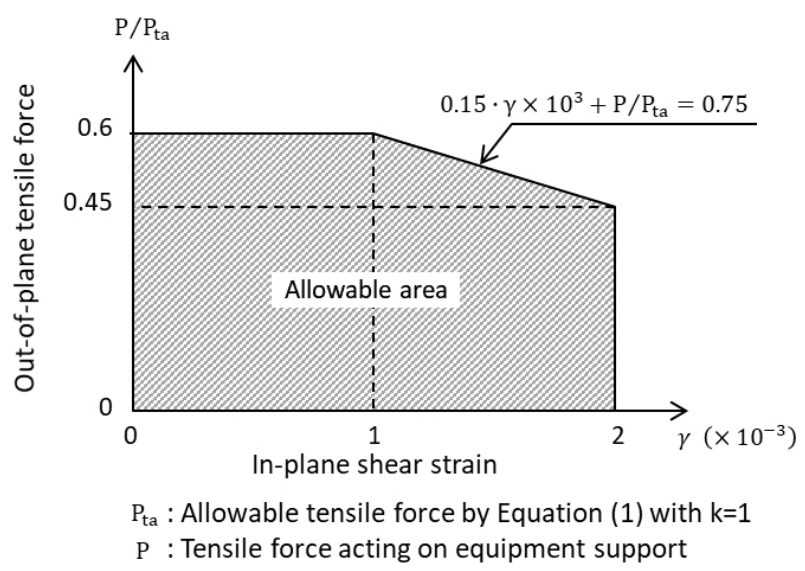

Fig. 15 Allowable area for in-plane shear strain and outof-plane tensile force (modified and translated according to JEAG 1991). 